\title{
Experimental Analysis of Liter of Night Light for Potential Use in Rural Electrification
}

\author{
Wubishet Degife ${ }^{\mathrm{a}}$, Wondwossen Bogale ${ }^{\mathrm{b}}$ \\ ${ }^{a}$ School of Mechanical and Chemical Engineering. Wollo University, Kombolcha Institute of Technology \\ ${ }^{\mathrm{b}}$ School of Mechanical and Industrial Engineering. Addis Ababa University, Addis Ababa Institute of Technology
}

Corresponding email: wubesvictory@gmail.com

\begin{abstract}
More than 1.1 billion people lack access to electricity in the world, among them 600 million are in sub-Saharan African countries. The socioeconomic life of the rural communities is highly affected by electricity supply. The demanding Interest for growth and development in developing countries led to a renewed interest of solar lights. Liter of night light is a solar powered light that is constructed from waste plastic bottles which lights up the rural community. This paper is about experimental analysis of liter of night light for potential use in rural electrification. The technology uses environmental friendly and locally available materials. The system is provided with battery storage, which allows it to operate for 13.5 hours continuously at full charge. Solar radiation is converted by PV solar panel to electric current. Circuit board is developed and fabricated to regulate and deliver consumable amount of voltage by the rechargeable lead acid battery. After testing five different solutions, the study found out that vinegar solution as the optimal solutions for the technology that can deliver 27lux of light to the surrounding. Simultaneously the study found out, that the light that is emitted from the bottle bulb is a function of volume, depth and solution type. And for this relationship curves are developed. And, the technology can be used for rural communities as it is.
\end{abstract}

\section{Keywords: Liter of light, Experimental Analysis, LED}

\section{Introduction}

According to[1] efforts to promote electricity access are having a positive impact in all regions, and the pace of progress has accelerated. IEA's analysis shows that the number of people without access to electricity fell to 1.1 billion people for the first time in 2016 , with nearly 1.2 billion people having gained access since 2000. The same report tells that there are still more people without electricity today than there were in 2000 . From this it is understandable that electrification 
growth is much slower than the population growth. The report also mentioned that $14 \%$ of the population still lacks access to electricity, $84 \%$ of which live in rural areas.

According to [2] combustible renewable resources (biomass, animal wastes, municipal and industrial wastes) largely dominate energy consumption in Africa. The same study mentioned, energy from biomass accounts for more than 30 percent of the energy consumed and more than 80 per cent in many sub-Saharan countries.

[3] Said that Sub-Saharan Africa, home to more than 950 million people, is the most electricitypoor region in the world. More than 600 million people lack access to electricity, and millions more are connected to an unreliable grid that does not meet their daily energy service needs. [4] reported that for the millions of people living in remote rural areas of Ethiopia who lack access to the power grid or cannot afford electricity, therefore, relaying solar energy appears as an option and hope for the rural community . Instead of relying on kerosene, candles, dry cell batteries and other fossil fuel-based sources of power.

[5] said that, liter of night light is as simple as a plastic bottle filled with water and integrated with small LED light powered by small PV panel could mean the difference between light and darkness. the almost no cost solution is uplifting the quality of life of thousands of impoverished families in the Philippines who have no access to electricity and use dangerous kerosene lamps indoors.

[6] unexpected high growth in the renewables market, in terms of investment, new capacity and high growth rates in developing countries have changed the landscape for the energy sector. The report states that the growth of renewables market contributed to falling prices and the increased decoupling of economic growth and GHG emissions. Due to this decoupling most countries have achieved a more diversified energy mix with a growth in community ownerships and an evolution of micro grids. According to [7] the pursuit of clean energy is at the heart of world's aspirations for a better future, as reflected in the 197 countries that have signed up to the Paris Agreement on Climate Change. As clean energy is moving from fossil fuels to renewable sources such as solar and wind is key to achieving social, economic and environmental development. Therefore, clean energy is a big concern for socioeconomic and environmental development. [8] Sub-Saharan nations are facing a lot of challenges for the planning of their future energy sector, especially the rural areas of Sub-Saharan nations are victims of scarcity of energy and this is due to lack of grid facilities, less financial and technical support, pressure from foreign institutions, excess of energy 
export. This all factors forces the rural community to relay on fossil fuels, but solely depending on fossil fuels will affect the life the rural community.

[9] said that due to energy, poor households suffer from a wide range of impacts, from increased risk of premature death due to indoor pollution to forgone productivity gains and lower quality of life. The same report outlines that on top of these impacts, energy-poor households must spend a greater proportion of their income to meet their basic energy needs. The rural community also sacrifices their time on engaging in energy intensive tasks than do wealthier households who have access to modern energy sources. Therefore, relying on fossil fuels have got socio economic and environmental impact.

According to [10] the open flame of kerosene lamps also poses as an obvious danger to households. Moreover, impoverished families spend up to half of their income on kerosene which not only provides inadequate illumination but also emits extremely harmful black carbon into the Earth's atmosphere. Kerosene lamps contribute to a vicious cycle of poverty that needs to be broken.

[11] said that rural electrification was not considered as a basic human need like water and food in the past. A number of recent studies provide insight into how rural electrification helps in the betterment of rural society in various ways. [12] studied that rural electrification results great benefits such as improvements of health facilities, better health from cleaner air as household reduce use of polluting fuels for cooking, lighting and heating, improved knowledge through increase access to television and better nutrition from improved knowledge and storage facilities from refrigerator.

[13] by increasing access to affordable lighting, communications and refrigeration, improved public health, and energy for productive activities, renewable energy systems offer an unprecedented opportunity to accelerate the expansion of energy access in remote and rural areas while at the same time contributing to the transition to modern energy services. Renewable energy can expand access to modern energy services in developing countries, both rapidly and cost effectively. Therefore, renewable energy is the only solution that can fill the gap. Among all renewable energy sources solar energy is the one to be considered for the rural communities as it can be used in a very small-scale application.

[14] said that that solar power is the conversion of sunlight into electricity. So, today, World is facing so many problems such as pollutions, water for drinking purpose, food problems, and electrical. yes, electricity problem is one of the major problem which is increasing rapidly day by 
day. (Mr. Bhawar Tushar,2016) said that in developing countries there isn't much source of electricity. Hence to use solar as largest source of energy one can build own solar based light bulb without any electricity cost. Many people do not have access to light or cannot cover the cost for electricity. Thus, they do not have light in their homes, even during the day. According to [15] everybody knows the importance of Solar Energy in today life. It is ultra clean, natural and sustainable source of energy that can be utilize in use of making solar electricity, solar heating appliances, solar lighting appliances and many more. The benefit to the local community above all is access.

According to [16] Liter of Light (Night) began by using the database of households with the daylight bottle bulbs in their roofs, the study mentioned that the technology upgrades 1-watt (\$10/unit) or 2-watt (\$15/unit) LED, with Pv solar and integrating with battery which would give another 10 hours of light at night. The study also mentions the system composure; as a simple circuit panel, drill and soldering, the night solar LED light is built and inserted into the already installed bulb.

[15] tried to study and compare the performance of liter of light with regular electric bulb, they said that the performance of the average brightness of solar bottle bulbs is almost similar to the conventional 40-Watt bulb. They have used for experimentation a single type of solution which is a soda bottle solar light. Though, they have made the comparison they don't put results in figures. Their study was limited only on a single solution and their results were not numerically available, therefore this reduces the trust of their research.

[17] studied on the critical view of solar bottle bulbs, and mentioned that, despite the positive aspects of solar bottle bulbs, peoples are not believing the ability of the technology to provide lighting, they said that this confusion is because of ; as there were no published experiments providing precise data regarding the performance and characteristics of light produced by these bottles, therefore there should be a study which can amend the people by justifying the performance of the technology. [18] studied the performance of solar bottle bulbs at different interior exposure levels. They said that different sizes and arrangements of solar bottle bulbs affect the lighting delivered and there is no general agreement on the best interior bottle exposure levels. From their study, they found that in terms of bottle exposure levels, the half level of the bottle performs best. But they were not capable of finding the parameters affecting that the best level to be at the middle of the bottle, they don't have studied that this property is for all solutions are for 
specific type of solutions. Though, many have tried to study the technology, none of the studies have tried designing the system in engineering way, only water have been used as a working fluid of the system, the impact of other fluids is not studied, the positioning of LED light in the system is arbitrary, its right position to give maximum possible amount of refraction from the system not studied and Depth, volume, solution type effect on the light refraction is not studied.

Therefore, all the mentioned gaps of the technology and the socioeconomic, health impacts of other technologies should be addressed. The solution for all mentioned limitations and gaps is having experimental analysis on liter of night light for better efficiency, that is why this study is very important.

\section{Methodology}

\subsection{Solar Panel Selection}

The solar panel collects the solar radiation from the sun and hence it is PV (photovoltaic); it converts the solar flux to electrical energy. There are three different types of solar panels: monocrystalline, polycrystalline and amorphous

For this purpose, Study, it is must to select the appropriate type of solar panel with best efficiency. Therefore, it is must to set criteria's

\section{Criteria's to Select Solar Panel Type}

Hence, selecting the appropriate type of solar panel is very important. Therefore, selecting criteria's which affect the systems efficiency and finance is must and cost, efficiency, Size and weight of the panel are selected as comparison criteria's

\section{Multi Criteria Decision to Select the Solar Panel}

In order to go through comparison, the criteria's must be weighted. The criterions are weighted using analytical hierarchical process (AHP) since the problem is decision making under certainty. The first step in AHP is determining the relative weights to rank the decision alternatives. Since there are 4 criteria's, a 4 by 4 pairwise comparison matrix A should be developed. Matrix A indicates the relative importance of the different criteria.

\begin{tabular}{|c|c|c|c|c|}
\hline & Cost & Efficiency & Size & Weight \\
\hline Cost & 1 & 1 & 3 & 5 \\
\hline Efficiency & 1 & 1 & 5 & 5 \\
\hline
\end{tabular}




\begin{tabular}{|c|c|c|c|c|}
\hline Size & $1 / 3$ & $1 / 5$ & 1 & 2 \\
\hline Weight & $1 / 5$ & $1 / 5$ & $1 / 2$ & 1 \\
\hline
\end{tabular}

To normalize the weights, the sum of each column is divided by the corresponding sum of each column. Then the normalized matrix $\bar{A}$ is given by

$$
\bar{A}=\left[\begin{array}{llll}
0.395 & 0.417 & 0.316 & 0.385 \\
0.395 & 0.417 & 0.526 & 0.385 \\
0.130 & 0.083 & 0.105 & 0.154 \\
0.200 & 0.083 & 0.053 & 0.077
\end{array}\right]
$$

Then, the weights of the criterions are found by taking the average values of each row as per AHP decision making process rules. And the weight matrix is given by;

$$
W_{T}=[0.37,0.43,0.12,0.08]^{T}
$$

Using the weights given in the transpose matrix the comparison has been made in the following table and the appropriate solar panel type is being selected based on the weight calculated for the criterions.

\begin{tabular}{|c|c|c|c|c|c|}
\hline \multirow{3}{*}{$\begin{array}{c}\text { Solar panel } \\
\text { Types }\end{array}$} & \multicolumn{4}{|c|}{ Criteria's } & \multirow{3}{*}{$\begin{array}{c}\text { Total } \\
\text { Percentage } \\
(100 \%)\end{array}$} \\
\hline & Cost & Efficiency & Size & Weight & \\
\hline & $(37 \%)$ & $(43 \%)$ & $(12 \%)$ & $(8 \%)$ & \\
\hline Monocrystalline & 25 & 43 & 12 & 8 & $88 \%$ \\
\hline Polycrystalline & 32 & 32.5 & 8 & 8 & $80.5 \%$ \\
\hline Amorphous & 37 & 17.2 & 6 & 3.2 & $63.4 \%$ \\
\hline
\end{tabular}

Table 2.1: Multi criteria decision for the solar panel selection

Therefore, based on the comparison monocrystalline solar panel is selected for the system.

\subsection{Capacity of The Solar Panel}

It is obvious now there are so many technologies in which LED lights are powered by solar power, as this project tries to find a way in which small solar panels to power small LED lights and then to refract the light using water to get large lux. Therefore, a monocrystalline solar panel with 3Watt power and 8.97 volts is selected, as this sized solar panels are most common in the local market of Ethiopia.

\subsection{Solar Battery sizing}

Depending on the solar panel solar battery manufacturers catalogue: for $8.97 \mathrm{~V}$ solar panel it is recommendable to use $6 \mathrm{~V}$ rechargeable lead acid battery. 


\subsection{Solar Battery Charging Circuit Design}

Figure 2.1 shows that the charging current passes to LM317 voltage regulator through the $1 \mathrm{~N} 4001$ Diode. The output voltage and current are regulated by adjusting the adjust pin of LM317 voltage regulator and then the battery is charged by the same current. LM317 Voltage regulators are always connected to $R_{1}(240 \Omega)$ as shown in figure 2.1 below therefore, other resistance Values $\left(R_{2}\right.$ and $R_{3}$ ) are determined depending on the output voltage required by battery.

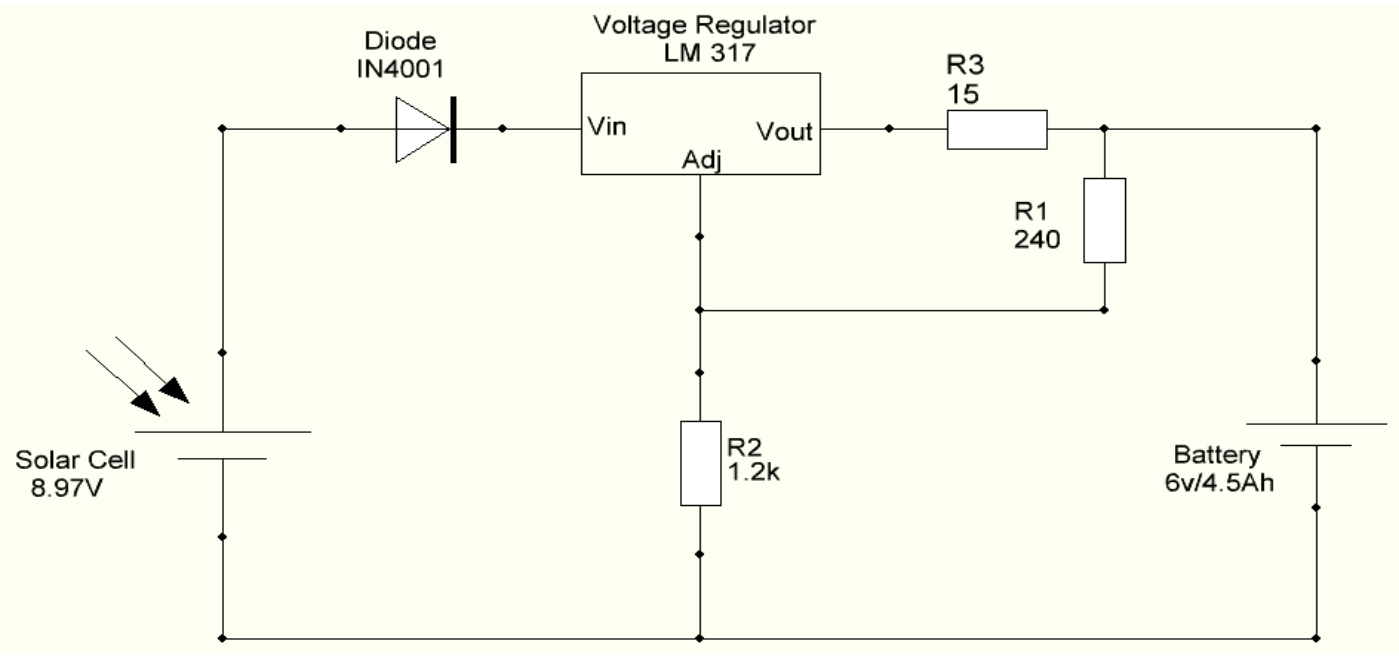

Figure 2.1: Charging Circuit

\subsection{Operation Principle of Charging Circuit}

According to principle of photovoltaic effect, the solar panel receive solar radiation during day time and convert it to electrical energy, as solar power varies with hours of the day, the voltage generated by the PV panel is not always constant. The battery should be supplied with constant voltage for charging, to do this LM317 voltage regulator is used and this regulator regulates the voltage generated by the PV panel to consumable amount by the battery. To protect the PV panel IN4001 diode is used, which allows current to flow in forward direction only.

\subsection{Charging Current}

The charging current which is the right current to charge the battery is calculated as follows: -

$$
\text { Charging Current }=\frac{\text { Solar panel Wattage }}{\text { Solar Panel Voltage }}=0.35 \mathrm{~A}
$$

Here LM317 voltage regulator can provide current up to $1.5 \mathrm{~A}$. Therefore, it is recommendable to this voltage regulator for the circuit developed above as the charging Current is below 1.5A. The 
battery selected requires maximum of $1.35 \mathrm{~A}$, from calculation the initial current is $0.35 \mathrm{~A}$ which is much less than the maximum and it remains safe.

\subsection{Charging Time}

$$
\text { charging time }=\frac{\text { Battery amper hour }}{\text { Charging Current }}=\frac{4.5 \mathrm{Ah}}{0.35 \mathrm{~A}}=12.85 \text { hours }
$$

The effective hours per day is 9 hours. Therefore, for the battery to be fully charged it takes 1.4 day.

\subsection{Power Dissipation}

Here the solar panel has 3 watts, the charging current was calculated in equation (1) above. Therefore, the power going in to the battery will be: -

power going in to the battery $=$ output voltage $\times$ charging current power going in to the battery $=8.97 \mathrm{~V} \times 0.35 \mathrm{~A}=2.12 \mathrm{watt}$

\subsection{Back Up Time of the Battery}

$$
\text { Back up time }=\text { watt hour of battry/Load }
$$

The total power of the LED light is about 1.5 watt, which is the load

$$
\text { Therefore, back up time }=4.5 \mathrm{Ah} * \frac{6 \mathrm{~V}}{1.3 \mathrm{watt}}=13.5 \text { hours }
$$

Assuming an average consumption of night light in the rural community to be 4 hours per day therefore, the system will run for 3.4 days.

\subsection{Design of lighting circuit}

Here below a single resistor and load is added to the charging circuit. Hence the battery selected is with capacity of $6 \mathrm{~V} / 4.5 \mathrm{Ah}$. Therefore, the circuit looks like as follow with 1.5-Watt LED light load. 


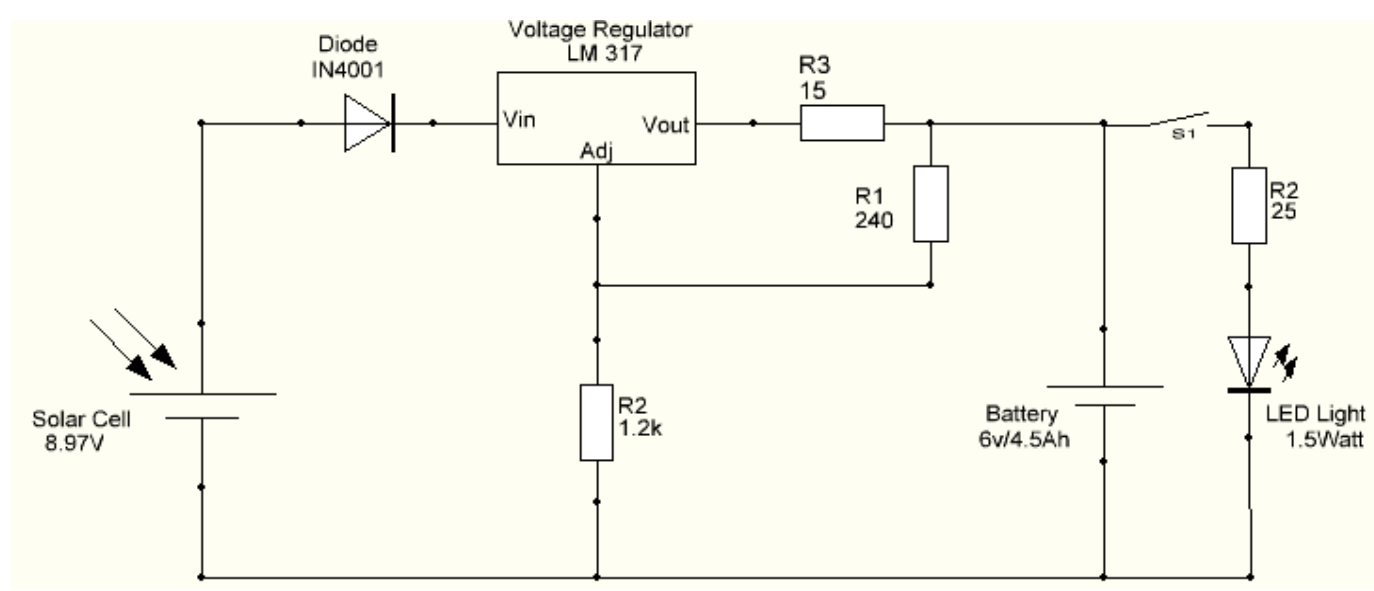

Figure 2.2: Lighting circuit

\subsection{Working Principle of Liter of Night Light}

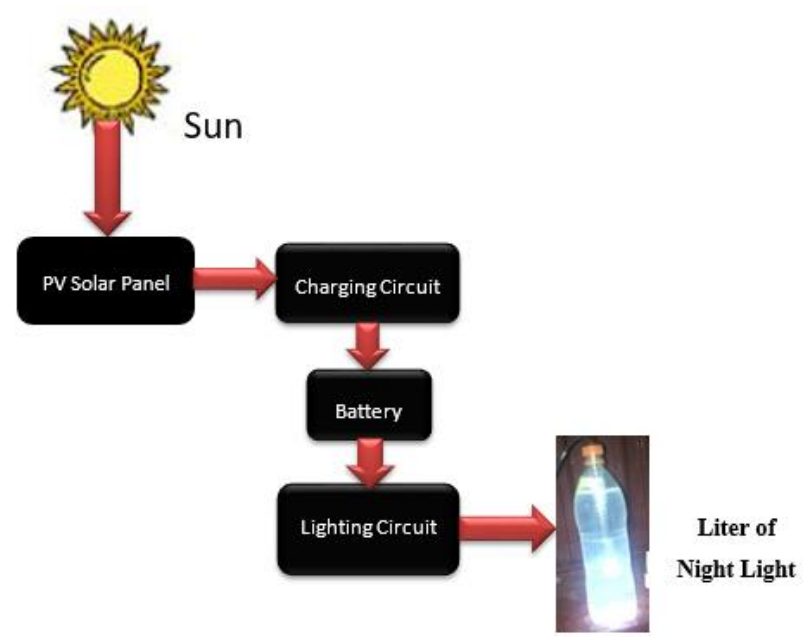

Figure: 2.3 Schematic Diagram of Liter of Night Light

The solar radiation is collected by PV solar panel, and the PV panel generates electric current. This voltage and current from the solar panel are regulated to consumable amount by the battery in the charging circuit. the electrical energy stored in the battery is regulated by the lighting circuit and delivered to the LED light inside a solution. This LED light is further refracted by the solution, and this depends on the type of solution used.

\subsection{Experimental Setup}

The experimentation was made in Ethiopian conformity assessment agency laboratory in a black room designed for lux measurement. The room area is about $9 \mathrm{~m}^{2}$ and for measurement the bottles are hanged two meters from the ground. The test was conducted using lux meter at 1-meter height 
from the ground. When measuring light using lux meter one should be aware of this, and it is mainly to deal with the fact that different wavelengths of light are not sensed equally by human eye. If all the wavelengths of contained the same intensity, the lux reading would be same but humans see more light of certain color and may say brighter but this is not always true. The materials used are: Lux Meter, Five 1-liter Pepsi plastic bottles, Black room (3m x 3m x 3m), Concentrated Salt Solution, Concentrated Sugar Solution Concentrated Sodium Bicarbonate Solution, Bottled Water and 5\% Vinegar Solution In water

\section{Results and Discussions}

\subsection{Experimental Results for LED Lights}

In order to compare the effect of the solutions 1.5-Watt LED light that has been tested. Accordingly, the amount of lux delivered by the LED light in the black room is measured to be 7.4 lux. Another light that has been tested is $7 \mathrm{w}$ alpha power emergency light. This bulb is rechargeable bulb and it was charged fully before the experiment. And, the light intensity measured is 19.3 lux.

\subsection{Experimental Result for Liter of Night Light}

\subsubsection{Solution Type Vs Light Intensity}

For experimentation 5 different solutions have been used. And the solution effect on the amount of light is studied by testing all the solution at specific heights.

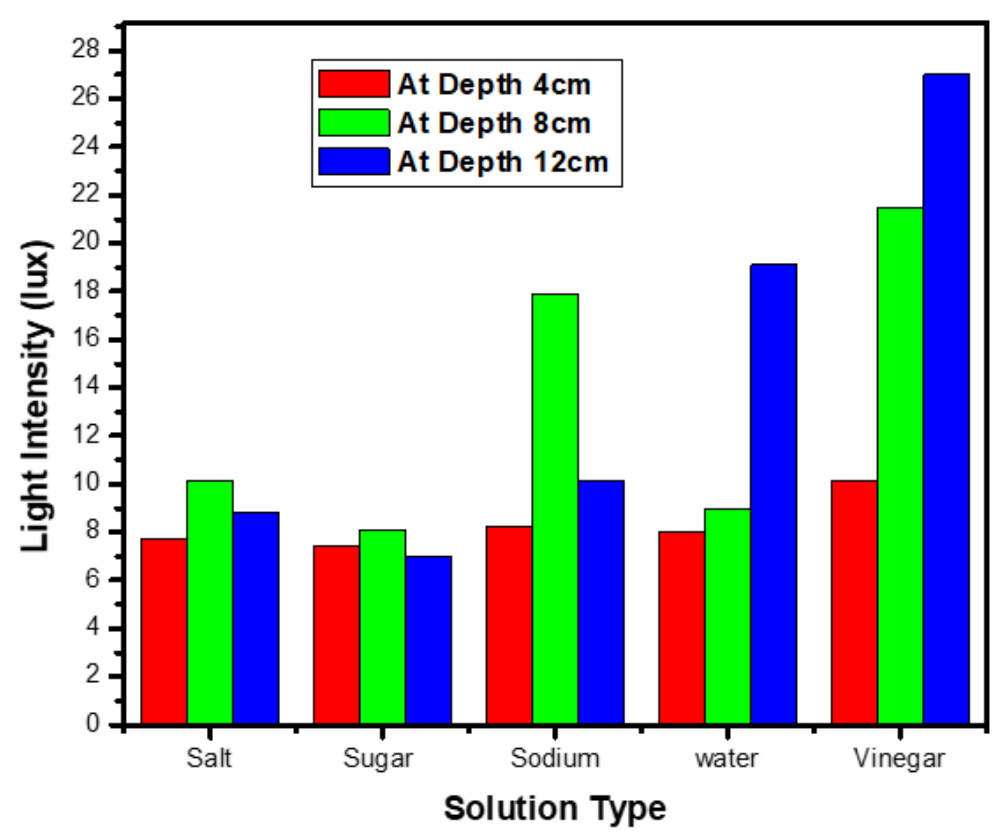


Figure 3.1 Light intensity Vs Solution Type

Figure 3.1 tells that vinegar solution light intensity increases with depth increment, also the water solution does the same, but the rate at which both solutions light intensity increment is different. For the same height increment both solutions should go in the same rate of increment but they didn't. Again, looking at salt, sugar and sodium bicarbonate solutions we can understand that they behave in different manner when compared to water and vinegar solutions. Therefore, the solution type has its own impact on the amount of light released out from the system. Finally, Vinegar solution is selected to be the best out of the tested solutions.

\subsubsection{Volume of the Solution Vs Light Intensity}

Figure 3.2 tells that as the volume varies the light intensity also varies and it is possible to say from the curves that light intensity is a function of volume. Hence, the light intensity is volume dependent, therefore the right volume amount for each solution should be determined. From Figure 3.2 the following best volume amount for each solution are found: The best volume for salt, Sugar, Sodium bicarbonate, bottled water and vinegar solutions are: $340 \mathrm{~cm}^{3}, 350 \mathrm{~cm}^{3}, 360 \mathrm{~cm}^{3}, 565 \mathrm{~cm}^{3}$, and $580 \mathrm{~cm}^{3}$ respectively.

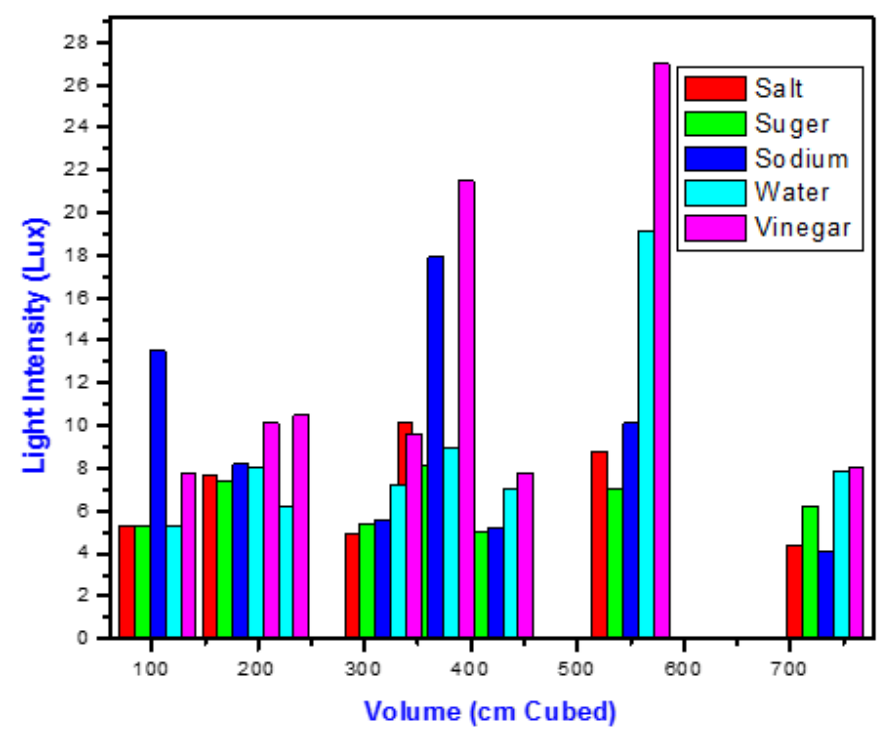

Figure 3.3: Volume of Solutions Vs Light Intensity

\subsubsection{Solutions Depth Vs Light Intensity}

Based on the figure 4.13 it is obvious to select the height as function of the solution to get best luminance out from the system. for each solution the best height is selected based on the experimental data. And the best depth of the solutions is listed below: -The best depth for the salt 
solution is around $8 \mathrm{~cm}$, for the sugar solution is around $8 \mathrm{~cm}$, for the sodium bicarbonate solution is $8 \mathrm{~cm}$, for bottled water is $12 \mathrm{~cm}$ and for for vinegar solution is about $12 \mathrm{~cm}$.

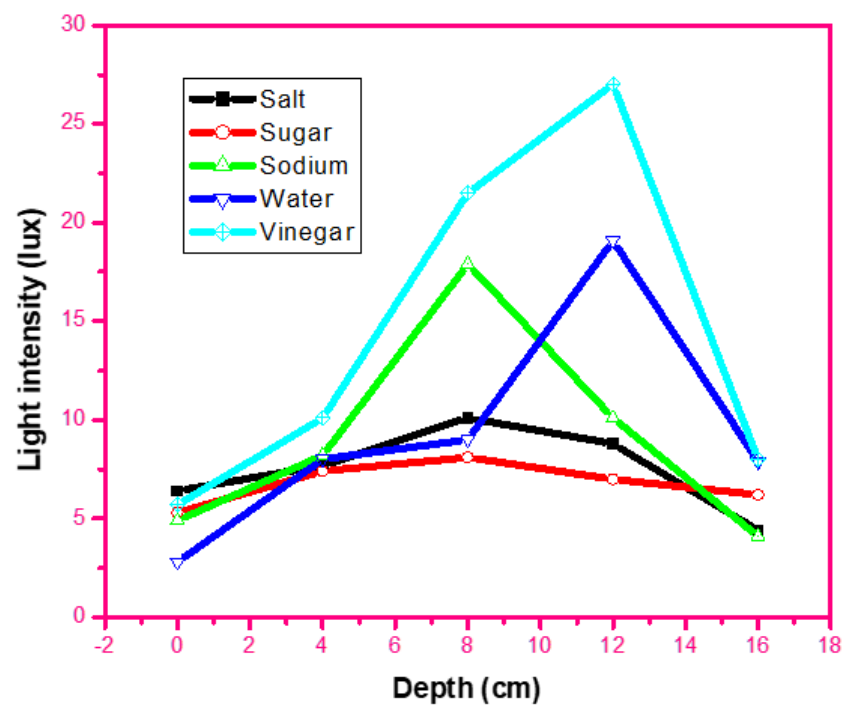

Figure 3.3: Solution Depth Vs Light Intensity

\subsubsection{Selection of Best System}

hence, our main target is selecting the best solution, with optimum volume and depth, the vinegar solution becomes the best out of all and its best volume is $580 \mathrm{~cm}^{3}$ and the LED light should be employed to these volumes about height equals $12 \mathrm{~cm}$.

for the system once, the volume and the height are given, it is not difficult to get the radius of our system, but in this case the radius is about 7.64 centimeters.

\subsubsection{Comparison of LED lights Intensity with the optimal liter of light}

Table 4.3: Comparison table LED lights with liter of night light technology

\begin{tabular}{|c|c|c|c|}
\hline S.no. & Name of the light bulb & Intensity & Rank \\
\hline 1 & LED light used for liter of & 7.4 & 3 \\
\hline 2 & $7 \mathrm{~W}$ alpha power emergency & 19.3 & 2 \\
\hline 3 & Vinegar solution liter of & 27 & 1 \\
\hline
\end{tabular}


From the table above the vinegar solution liter of night light is much greater than the source LED light and the alpha power emergency light. Therefore, it is very crucial to employ this vinegar lights to the community.

\subsubsection{How to Use Vinegar Solution Liter of Night light level for $9 \mathrm{~m}^{2}$ room}

According to Panasonic standard of light amount in Appendix A6, the recommended light level for a living room is about 50 Lux. But the vinegar solution delivers 27 Lux only in a $9 \mathrm{~m}^{2}$ room. Therefore, installing two vinegar plastic bottle bulbs will solve the problem. Concluding, for $9 \mathrm{~m}^{2}$ room two vinegars solution bottle bulbs can glow the light amount specified by Panasonic standards.

\section{Conclusions}

The goal of this thesis was to select best liter of night light system by performing experimental analysis. To get ready our system for experimentation the electrical circuit has been designed, and then suitable materials for the technology are selected. The system was developed by assembling all materials as per the design and experimentation was performed. After experimentation, the results have been recorded and analyzed and on the following conclusions are found. Firstly, almost all PV systems are controlled by charge controllers, but this system is controlled by LM317 voltage regulators these increases the easiness of the technology. Secondly, the liter of night light technology is dependent on the solution used to refract the light out from it. Five different solutions are tested and five of them have shown different capacities of refracting light. In methodology section it was believed that solutions with higher refractive index will refract light in better way than solutions owning lesser refractive index. But, the situation after experimentation explains how the premises was wrong as vinegar which is with much lesser refractive index than Salt and Sugar solutions becomes the best solution. Therefore, there should be other properties that are not studied in this thesis. Thirdly, it was found that the amount of light refracted from the system is a function of the depth, volume of the solution. These relationships vary from solution to solution, Salt and sugar solutions operate good at a depth of $8 \mathrm{~cm}$ in $7.64 \mathrm{~cm}$ container. While Vinegar and bottled water function good at a depth about $12 \mathrm{~cm}$ in the same container. It was able to find an equation that explains the relationship between Lux and Volume, and also Lux and Depth of the solution. Fourthly, among the tested solutions vinegar solution has been found to be best, even that the LED light should be employed in the appropriate depth and volume unless it will not give the desired amount of light, Fifthly, the vinegar solution based liter of night light is much better than alpha 
power 7watt Emergency light which is now in controlling the market. So far it has been done a strained effort on the project; It is recommended that to study the shape factor of the solution container and using the technology as per this design is can be a solution rural community's problem.

\section{References}

[1] IEA, "Energy Access Outlook 2017: From poverty to prosperity," p. 144, 2017.

[2] UNEP, “Atlas of Africa Energy Resources,” 2017.

[3] N. Avila, J. P. Carvallo, B. Shaw, and D. M. Kammen, "The energy challenge in subSaharan Africa: A guide for advocates and policy makers Part 1 : Generating energy for sustainable and equitable development," oxfam Res. Backgr., vol. Part 1, 2017.

[4] “Off-Grid Solar Lighting Up Ethiopia," 2016. [Online]. Available: http://www.worldbank.org/en/news/feature/2016/08/15/off-grid-solar-lighting-upethiopia. [Accessed: 05-Dec-2017].

[5] Inhabitat, "1 Liter of Light Project Illuminates Thousands of Filipino Homes With Recycled Bottles | Inhabitat - Green Design, Innovation, Architecture, Green Building.” [Online]. Available: https://inhabitat.com/1-liter-of-light-project-illuminates-thousands-offilipino-homes-with-recycled-bottles/. [Accessed: 05-Dec-2017].

[6] World Energy Council, “World Energy Resources 2016,” World Energy Resour. 2016, pp. $1-33,2016$.

[7] A. McCrone, U. Moslener, F. D’Estais, and C. Grünig, “Global Trends in Renewable Energy Investment 2017," Frankfurt Sch. UNEP Collab. Cent. Clim. Sustain. Energy Financ., p. 90, 2017.

[8] B. Khan and P. Singh, "The Current and Future States of Ethiopia's Energy Sector and Potential for Green Energy: A Comprehensive Study,” Int. J. Eng. Res. Africa, vol. 33, pp. 115-139, Nov. 2017.

[9] N. Avila, J. P. Carvallo, B. Shaw, and D. Kammen, "The energy challenge in sub-Saharan Africa: A guide for advocates and policy makers. Part 2: Addressing energy poverty," Oxfam Res. Backgrounder, no. January, 2017.

[10] UNESCO, “The International Year of light and Light-based Technologies 2015," 2015.

[11] T. Buragohain, "Impact of Solar Energy in Rural Development in India," Int. J. Environ. Sci. Dev., vol. 3, no. 4, pp. 0-4, 2012. 
[12] IEG, The Welfare Impact of Rural Electrification: A Reassessment of the Costs and Benefits. An Independient Evaluation Group (IEG) Impact evaluation. 2009.

[13] J. Fitch, "Electrification in California :," Rural elctrification Vanuatu, no. United Nations Deveolpment Programme, pp. 1-124, 2009.

[14] V. R. Bansod, "Study on Solar Water Bulb-a Liter of Light," vol. 1, no. 10, pp. 256-259, 2015.

[15] P. K. . P. Mr.Bhawar Tushar, "Design \& Development of Solar Bottle Bulb \& Mobile Charger," vol. 3, no. 2, pp. 170-173, 2016.

[16] Building and Social Housing Foundation, "Liter of light Lighting homes and lives one bottle at a time," 2014.

[17] C. Wang, F. A. M. Rahim, N. S. M. Yusoff, H. A. Rahman, and V. How, "Critical View on Daylighting Through Solar Bottle Bulb," Build. Res. J., vol. 61, no. 2, pp. 115-128, 2015.

[18] H. A.-R. C Wang, VL HOW, "The performance of solar bottle bulbs at different interior exposure levels," SAGE journals, vol. Vol 47, no. 1,2015, 2013. 